Marie-Pierre Dargnies*

\title{
Social Identity and Competitiveness
}

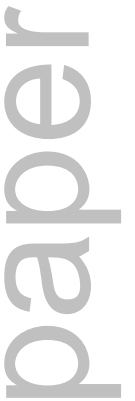

Discussion Paper SP II 2011-202

March 2011

Social Science Research Center Berlin (WZB)

\author{
Research Area: \\ Markets and Politics \\ Research Unit: \\ Market Behavior \\ http://www.wzb.eu/mp/vam \\ E-mail: dargnies@wzb.eu
}

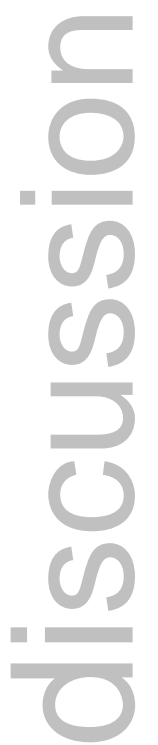

Wissenschaftszentrum Berlin für Sozialforschung (WZB) •

Reichpietschufer 50 • D-10785 Berlin • www.wzb.eu 
(c) The copyright remains with the authors

Marie-Pierre Dargnies

Social Identity and Competitiveness

Discussion Paper SP II 2011-202

Wissenschaftszentrum Berlin für Sozialforschung (2011)

* I am grateful to Guillaume Hollard, Marie-Claire Villeval, Lise Vesterlund, Muriel Niederle, Guillaume Fréchette, Jean-Christophe Vergnaud and Matthias Sutter for their comments.

Social Science Research Center Berlin (WZB)

Research Area:

Markets and Politics

Research Unit:

Market Behavior
Wissenschaftszentrum Berlin für Sozialforschung gGmbH (WZB)

Forschungsschwerpunkt:

Märkte und Politik

Abteilung:

Verhalten auf Märkten

Reichpietschufer 50, D-10785 Berlin

Telefon: +49 30 25491-0, Fax: +49 30 25491-440

http://www.wzb.eu 


\begin{abstract}
Recent experimental results indicate that women do not like competitive environments as much as men do. Another literature is interested in the effect of social identity on economic behaviors. This paper investigates in the lab the impact of social identity on men and women's willingness to compete both individually and as part of a team. To this aim, participants from the Identity sessions had to go through group identity building activities in the lab while participants from the Benchmark sessions did not. The main result is that men are only willing to enter a team competition with a teammate of unknown ability if they share a common group identity with him or her. This change of behavior seems to be caused by high-performing men who are less reluctant to be matched with a possibly less able participant when he or she belongs to his group. On the other hand, group identity does not seem to induce women to take actions more in the interest of the group they belong to.
\end{abstract}

Keywords: Social Identity, Gender Effects, Tournament, Teams 


\section{Introduction}

Women are widely under-represented in top-level social positions. While several potential reasons may explain this fact (Goldin and Rouse, 2000, Altonji and Blank, 1999), recent findings have emphasised one specific cause as particularly relevant: women are less likely to self-select into competitions (Gupta et al., 2005, Niederle and Vesterlund, 2007, Niederle et al., 2008).

Dargnies (2009) shows that many men stay out of competition when it is team-based so that there is no gender gap in team tournament entry. This result is mainly due to high-performing men being repelled by the idea of helping a probably less able participant increase her payoffs. Indeed, high-performing men are willing to enter the team tournament, but only provided that they will be matched with a teammate of level close to their own. While high-performing men have an obvious interest in being matched with another highly efficient teammate, this may also suggest that they gain utility from performing with a teammate they share characteristics with. In other words, being in the same team sometimes means something more than a change in expected payoffs. If such is the case, performing at a similar level may act as an implicit common identity. It is then interesting to study whether an explicit, artificially-created, group identity would have similar effects. Indeed, a lot of competitions oppose groups of individuals who share some attributes whether it is a sport game opposing two nations or two firms competing for clients.

The aim of the present article is to study how the creation of a group identity affects men and women's willingness to enter competitive environments.

The impact of group identity on economic behaviors has lately become of keen interest to economists. Standard economic theory assumes economic agents act as isolated individuals. However, individuals often perceive themselves as member of social groups and this may well have an impact on the decisions they have to make. If such is the case, understanding how group identity affects economic decisions would be crucial. ${ }^{1}$ Akerlof and Kranton emphasize how social identity may affect economic outcomes (Akerlof and Kranton, 2000, 2002, 2005). Following their work, experimental economists have been interested in studying how social identity changes individual behavior. Converging results indicate that individuals take more socially-oriented decisions when they deal with fellow group members rather than with random participants or outgroup members. For instance, Chen and Li (2009) finds that participants behave more altruistically with an ingroup match than with an outgroup. Charness et al. (2007) show that when group membership is made salient, either by common

\footnotetext{
${ }^{1}$ The social identity theory has been developped by Tajfel (Tajfel, 1970, Tajfel et al., 1971, Tajfel and Turner, 1979, 1986).
} 
payoffs or by letting an audience of group members watch the decision-maker, decisions tend to favor more the payoffs of the whole group. Eckel and Grossman (2005) also find that a strong enough social identity increases cooperation significantly among the group. Given these results, one should expect social identity to influence decisions to compete, especially as part of a team. In an investment experiment, Sutter (2009) finds that the decisions made individually by one group member are very similar to the decisions taken jointly by all the members of a team.

The experimental design of this article is based on that of Dargnies (2009) and compares the competitive behavior of subjects who have been through preliminary "group identitybuilding" activities (Identity sessions) to that of subjects who have not (Benchmark sessions). I chose to artificially create a group identity in the lab so as to be able to control for whatever subjects bring into the lab. When entering the room, participants from the Identity sessions were randomly assigned to one of two groups and could communicate within their group through an instant message system in order to choose a name for their group. They then had to perform a collective task during which they could also use the instant message system to communicate with the members of their group. After this first "group identity creation" phase was over, participants were not able to communicate. The second phase of the Identity sessions corresponds to the experimental design of Dargnies (2009): Participants had to go through several tasks for which their payoffs depended on how many additions they could solve in a given period of time. At some points, they were asked to make choices between two available remuneration schemes, one individual - a piece rate- and one that is team-based. In the Identity sessions, one's teammate belonged to her group and one's opponents belonged to the other group, while, in the Benchmark sessions, one's teammate and opponents were just participants present in the room. The choices made during the second phase of the Identity sessions were compared to those made during the Benchmark sessions for which there was no previous attempt to build a group identity.

If one of the reasons why high-performing men engage in team competition only with a teammate of the same level is because they need to share a common characteristic with their teammate, one would expect high-performing men to enter team competition at higher rates when their teammate is a fellow group member. Since team competition makes women a little more likely to enter the tournament, one could expect group identity to further increase women's willingness to enter the team tournament.

The main result is that, while high performing men from the Benchmark sessions were not willing to enter the team competition unless they were matched with a teammate of the same level, it was not the case in the Identity sessions where men did not opt out from the 
team competition when their teammate was a fellow group member. Indeed, high-performing men are less reluctant to be matched with a possibly less able participant when he or she belongs to his group. It then seems that high-performing men are not likely to enter a team competition unless they know their teammate will either be of level close to their own or share a social identity with them. This result suggests that men are more comfortable working with teammate belonging to the same clique as they do and this could help explain why a very high percentage of people get their job through friends or relative (Montgomery, 1991).

I also found that women's competitive behavior is not much affected by the group identity. If anything, somehow surprisingly, women, and more precisely low-performing women, are less willing to enter competitive environments when being a member of a group and they are somehow less afraid of dragging down a possibly more efficient teammate when he or she belongs to her group than when he or she is a random participant. The most likely explanation for this unexpected effect of group identity on women's competitiveness is that women may be that the specific group identity building activities implemented in this experiment failed at instilling to women a sense of belonging to the group and actually made them uncomfortable. If such is the case, it would not necessarily mean that women cannot respond positively to group identity in real life.

All in all, it seems important for managers to encourage a team culture in their work group since it makes men willing to cooperate with less competent coworkers. It may well have positive externalities as it is likely that new employees have a lot to learn from cooperating with more senior workers. Women might also enjoy the feeling of belonging to a group and be more willing to enter competitions with someone they share a common identity with provided this identity was acquired through time.

The rest of the article is organized as follows. The experimental design is presented in section 2. Section 3 provides the results and section 4 discusses them. Finally, section 5 concludes.

\section{Experimental Design}

This paper compares the competitive behavior of subjects who have been through groupidentity-building activities (Identity sessions) to that of subjects who have not (Benchmark sessions). In the Identity sessions, participants were randomly separated in two groups and had to participate in activities meant to create a group identity before going through 8 tasks. In the Benchmark sessions, participants directly went through the 8 tasks without 
previously experiencing the creation of a group identity. During those 8 tasks, subjects had to participate to one tournament and had several opportunities to choose to enter tournaments. In the Identity sessions, one's opponent(s) in the tournaments one engaged in were members of the other group and her teammate, if she had any, belonged to the same group as her own. On the other hand, in the Benchmark sessions, one's tournament opponent(s) and teammate were just participants present in the room.

\subsection{Identity sessions}

\subsubsection{Creation of a Group Identity}

Subjects entered the experimental laboratory and each sat in front of a computer. They were randomly assigned to one of two groups by the computer but did not know who was and was not part of their group. The group-identity-building activities consist of two parts during which the participants are able to chat with their fellow group members through an instant message system. Firstly, participants of each of the two groups are given two minutes to find a name for their group. The aim of this first activity is to create a sense of belonging to the group. Secondly, they have to answer a short quiz. Again, as members of a group have to communicate in order to find the correct answer, they should get the feeling that they can rely on other group members in order to achieve a common goal.

Choice of a Group Name: Participants were told that they had two minutes to communicate through a chat program on their computers with the other group members to find a name to their group. Two chat programs were set so that communication was possible within the members of each group but participants of different groups could not communicate. After the two minutes were up, each participant had to enter his or her choice of group name. If all members of a group did not agree on a name, the name that most members chose was considered to be the group name. The names of both group were publicly announced by the experimenter so as to further help trigger a sense of group membership.

Quiz: Participants had to answer to a four questions quiz. Since participants did not know each other previous to the experimental session, it seemed necessary to add a group activity to the choice of a group name. For each question, four possible answers were available and participants had two minutes to discuss what they thought was the correct answer within their own group. At the end of the two minutes, each participant had to enter his or her answer knowing that the answer validated for the whole group would be the one chosen by a majority of members. Each member could earn 1 euro if the answer validated for his or her group was correct. Participants did not learn the correct answer and the answers chosen by 
the other members of their group until the end of the experiment.

Previous experiments used various tricks to enhance a sense of membership to the group. Brown-Kruse and Hummels (1993) made participants answer a questionnaire (which Solow and Kirkwood (2002) used as well) including questions such as the best book they had read lately or their favorite flavor of ice-cream and the answers of each group member were made public to the other members. Participants could not identify their fellow group members. Eckel and Grossman (2005) used several treatment each corresponding to a more or less strong way of creating a group identity. In one treatment, participants were assigned to a color group and wore a tag of the corresponding color so that all subjects could witness the membership of every other participant. In another one, subjects were divided into groups depending on the answers they had given to a quiz. In a last one, subjects had to complete a group task. In each of these treatments, a participant could identify all of his group members. Chen and Li (2009) divided their subjects into two groups according to their painting preferences (Kandinski vs Klee) and group members remained anonymous. In the

present experiment, it seemed important to make team membership anonymous (one could not know which participants belonged to his or her own group) so that one would not have to worry about having to answer to the members of her group about her performance and whether she chose to enter the different tournaments. It also appeared crucial to have group members engage in a common activity in order to instill a sense of group membership.

\subsubsection{The Tasks}

This part of the experimental design builds on that of Niederle and Vesterlund (2007), henceforth NV. The exercise subjects were asked to perform is the same as in NV: additions of five 2-digit numbers.

Participants were told that they had to complete eight tasks of which two would be randomly chosen for payment at the end of the experiment. At the end of each task, participants were informed of their absolute performance (the number of additions they correctly solved) but were not informed of their relative performance until the end of the experiment. In a standard task, participants had to choose between a piece rate and a remuneration scheme involving competition (a tournament) before having three minutes to solve as many additions as they could. The compensation schemes available changed between tasks and participants were informed of their nature only immediately before performing the task. Each time a tournament was available, participants were informed that their opponents would be members of the other group while their teammate, in the case of team competition, would be a member of their own group. I made the participants from the Identity sessions go through 
the 8 same tasks as the participants from the Benchmark sessions so as to be able to properly compare the behaviors of participants from both kinds of sessions. This section details the tasks participants had to go through.

Task 1. Piece Rate: Participants are given the three-minute addition exercise. If Task 1 is randomly chosen for payment, they receive 50 cents per correct answer.

Task 2. Individual Tournament: Participants are given the three-minute addition exercise. If Task 2 is chosen for payment, the subject receives 1 euro per correct answer if she solved more additions than her opponent randomly chosen among the other group, otherwise she receives nothing.

Task 3. Choice between Piece Rate (PR henceforth) and Individual Tournament (IT henceforth): Before they perform their additions, subjects have to choose whether they want to be paid according to the Piece Rate (50 cents per correct answer) or the Individual Tournament compensation scheme. A participant who selects the tournament receives 1 euro per correct answer if her Task 3 performance exceeds the Task 2 performance of her opponent randomly chosen among the other group, otherwise she receives nothing. Subjects are competing against a past competitive performance of their opponent so that the decision to enter the tournament is not affected by beliefs about whether the opponent is going to enter. In addition, it allows one to rule out the possibility that a participant may not enter because she may fear to inflict losses on her opponent.

Task 3 prime. Choice between submitting Task 1 performance to Piece Rate or Individual Tournament: No additions to do here, the performance which will determine the payoff is the Task 1 performance. If a participant chooses to submit her Task 1 performance to the Piece Rate, she receives 50 cents times her Task 1 performance. If she chooses to submit her Task 1 performance to the Individual Tournament, she receives 1 euro per addition correctly solved in Task 1 if she solved more additions than her opponent randomly chosen among the other group, otherwise she receives nothing. Task 3 prime is identical to Task 3 (in both cases the tournament is a more risky choice implying more ambiguity and subjecting the participant to feedback at the end of the experiment concerning whether she beats her opponent) except for the fact that it does not involve a future performance. In particular, the participant who chooses to submit her past performance to the tournament does not have to perform under the pressure of competition. In consequence, any change in behavior between Tasks 3 and 3 prime will be attributed to the taste for performing in a competitive environment.

Task 4. Choice between Piece Rate and Team Tournament: Subjects have to choose whether they want to be paid according to the Piece Rate or the Team Tournament. The 
Team Tournament is a two to two competition. If a participant chooses the Team Tournament, two opponents are randomly drawn among the members of the other group. One teammate is randomly drawn among the members of the participant's group who chose the Team Tournament. ${ }^{2}$ This implies that a subject who chooses to enter the Team Tournament knows that her teammate will have made the same choice so that both teammates will be competing at the same time against their opponents, facilitating the emergence of a team spirit. If the number of additions solved by one's team during Task 4 exceeds the number of additions solved by the opposing team during Task 2, each teammate receives 1 euro times the average score of their team. Otherwise, they receive nothing.

Task 4 prime. Choice between submitting Task 1 performance to Piece Rate or Team Tournament: No additions to do here, the performance which will determine the payoff is the Task 1 performance. If a participant chooses to submit her Task 1 performance to the Piece Rate, she receives 50 cents times her Task 1 performance. If she chooses to submit her Task 1 performance to the Team Tournament, two opponents are randomly drawn among the members of the other group. One teammate is randomly drawn among the members of the participant's group who chose to submit to the Team Tournament. ${ }^{2}$ If the number of additions solved by one's team during Task 1 exceeds the number of additions solved by the opposing team during Task 1 , each teammate receives 1 euro times the average score of their team. Otherwise, they receive nothing. Task 4 prime is identical to Task 4 (considering overconfidence, risk aversion and uncertainty about teammate's ability) except for the fact that it does not involve a future performance. In particular, the participant who chooses to submit her past performance to the Team Tournament does not have to perform under the pressure of competition. In consequence, any change in behavior between Tasks 4 and 4 prime will be attributed to the taste for performing in a team competition.

Task 5. Choice between Piece Rate and Team Tournament with a teammate of the same level (TTid henceforth): If a participant chooses the Team Tournament with a teammate of the same level, two opponents are randomly drawn among the members of the other group. One teammate is attributed from among the members of the participant's group who chose the Team Tournament: the participant whose Task 2 performance was the closest to the participant's own Task 2 performance. If the number of additions solved by one's team during Task 4 exceeds the number of additions solved by the opposing team during

\footnotetext{
${ }^{2}$ If only one member of a group had chosen the team tournament, which never happened, she would have been matched with a member of her group who had chosen the piece rate. Also, if an uneven number of group members chose the team tournament, participants were paired and a teammate was randomly chosen among them whose performance was added to the remaining participant's performance to compute the score of her team
} 
Task 2, each teammate receives 1 euro times the average Task 5 score of their team. Task 5 resembles Task 4 in that the subjects have to choose between a Piece Rate remuneration and a Team Tournament but in Task 5 the uncertainty about one's teammate's ability at solving additions (or at least part of it) is taken away. Then, assuming that learning effects are the same for men and women, if men's and women's behavior changes in a different way between Task 4 and Task 5 , it will be attributed to a different reaction to the uncertainty about one's teammate's ability.

Task 5 prime. Choice between submitting Task 1 performance to Piece Rate or Team Tournament with a teammate of the same level: No additions to do here, the performance which will determine the payoff is the Task 1 performance. If a participant chooses to submit her Task 1 performance to the Piece Rate, she receives 50 cents times her Task 1 performance. If she chooses to submit her Task 1 performance to the TTid, two opponents are randomly drawn from among the members of the other group. One teammate is attributed from among the members of the participant's group who chose the Team Tournament: the participant whose Task 2 performance was the closest to the participant's own Task 2 performance. If the number of additions solved by one's team during Task 1 exceeds the number of additions solved by the opposing team during Task1, each teammate receives 1 euro times the average score of their team. Otherwise, they receive nothing.

\section{Belief-assessment Questions}

A difference in confidence between men and women may explain a significant part of the gender gap in tournament entry. Niederle and Vesterlund (2007) and Niederle et al. (2008) found that both men and women are overconfident but men are more so. In order to control for differences in confidence both in one's chances of winning the Individual Tournament and in one's team chances of winning the Team Tournament, participants had to answer beliefassessment questions at the end of the experiment. Participants had to guess the mean Task 2 performance of members of their own group and of the other group.

The participants were recalled that during Task 4 they had to choose between a Piece

Rate and a Team Tournament, for which two opponents were randomly drawn from among the members of the other group and a teammate was randomly drawn from among the members of the participant's group who had chosen the Team Tournament. They were also told that even if they had chosen the Piece Rate at Task 4, two opponents and one teammate had still been randomly chosen in the exact same way. Their own Task 2 performance was recalled to them and participants had to guess the Task 2 performances of their teammate and opponents chosen during Task 4.

A participant knew she would earn 1 euro per correct guess. 


\subsection{Benchmark sessions}

The experimental design in the Benchmark sessions was the same as that of Identity sessions, except that participants did not go through the creation of a group Identity but started with the tasks. Also, in each tournament the participant had or wanted to participate in, her opponent(s) were randomly chosen among all the other participants present in the room and, in the case of the team tournament (TT) and team tournament with a teammate of the same level (TTid), her teammate was one of the other participant present in the room who also chose to enter the same team tournament.

\section{Results}

The experiment was run at the Parisian Experimental Economics Laboratory (LEEP) of Paris 1 University. ${ }^{3}$

39 men and 37 women took part in the Benchmark sessions, while 52 men and 38 women participated in the Identity sessions adding up to a total of 166 participants. There were 6 Benchmark sessions and 5 Identity sessions. The average participant earned 15,86 euros in the Benchmark sessions and 17.38 including a 7-euro show-up fee.

In this section, after describing the unfolding of the group identity building activities, I investigate how group identity affects performance and the decision to enter the individual tournament. I then study the effect of group identity on team tournament entry. Finally, the different impact of group identity for men and women is analyzed.

\subsection{Group identity building activities}

In the Identity sessions, the first thing subjects had to do was use the instant message system to find a group name with their fellow group numbers. The name chosen for each of the two groups in each of the 5 sessions were ${ }^{4}$ : Groupex (for experimental group), FunBossTeam, Cosmos, Icare (Icarus), Jackson, Bogoss (phonetic for "beaux gosses" which approximately means hot guys), Cobaye (Guinea Pig), Groupe 1 (Group 1), Happy Face and Cosmopolites. Depending on the sessions and the groups, the group members were more or less fast in reaching a consensus. In order to take these differences into account, in the following of the article, session dummies were added in the regressions concerning the participants to the Identity sessions. Nevertheless, the coefficients of these sessions dummies were never found

\footnotetext{
${ }^{3}$ Subjects were recruited through the online recruitment system ORSEE (Greiner, 2004). The experiment was computerized using the REGATE software (Zeiliger, 2000).

${ }^{4}$ If needed, the translation is in brackets.
} 
to be significant, suggesting that the response to group identity does not depend heavily on the session one belonged to.

\subsection{The effect of social identity on performance, confidence and entry in the individual tournament}

In this subsection, the changes in performance, confidence and decision to enter the individual tournament between subjects who have not experienced the creation of a group Identity and those who have are investigated.

\subsubsection{How social identity impacts performance and confidence in one's chances of winning the individual tournament}

For both men and women, the Task 1 and Task 2 performances are lower among participants with a group Identity. However, the difference is significant only for the Task 2 performance

of men (a two-sided Mann Whitney test yields $p=0.05$ ) who solved on average 7.4 additions during the Benchmark sessions and 5.9 during the Identity sessions. Furthermore, while men from the Benchmark sessions performed significantly $(p=0.04)$ better under the tournament remuneration scheme (Task 2) than under the piece rate (Task 1), such is not the case in the Identity sessions in which performances are not significantly different between Task 1 and 2 neither for men $(p=0.12)$ nor for women $(p=0.51)$.

In addition to performance, what may also explain the decision to enter the individual tournament is the confidence in one's chances of winning the tournament. In order to make it possible to compute a measure of overconfidence, participants had to answer several beliefassessment questions. In particular, they had to guess the Task 2 performance the average participant of their session. Subjects taking part in the Identity sessions also had to guess the Task 2 performance of the average member of the other group. From these answers, the dummy variable guesswin equal to 1 if the participant's beliefs are consistent with winning the tournament, and to 0 otherwise, was computed in the following way. In the Benchmark sessions, guesswin is set equal to 1 if a subject thinks the Task 2 performance of a randomly chosen participant is lower or equal to her own Task 2 performance, and to 0 otherwise. In the Identity sessions, guesswin is set equal to 1 if a subject thinks the Task 2 performance of a randomly chosen member of the other group is lower or equal to her own Task 2 performance, and to 0 otherwise. Given Tajfel (1970)'s results who found that minutes are sufficient for individuals, who have been divided into different groups following minimal criteria, to feel their own group as superior, one would expect subjects from the Identity sessions to be more 
confident in their chances of winning than subjects from the Benchmark sessions.

$78 \%$ of women in the Benchmark sessions and $58 \%$ in the Identity sessions think they are likely to win the individual tournament. This difference is significant (a two-sided Fisher test yields $p=0.08$ ) indicating that women who experienced the creation of a group Identity are actually less confident than those who did not. One explanation for this could be that the group identity building activities actually made women uncomfortable therefore decreasing their confidence in their chances to beat their opponents. Another reason could come from the different sex ratio between the Benchmark and the Identity sessions. Indeed while the Benchmark sessions are composed of almost the same number of men and women (39 vs 37 ), there are more men than women in the Identity sessions (52 vs 38). If women believe that men are on average better than women, this could explain why they are less confident in their chances of winning when they are more likely to be competing against a man. ${ }^{5}$ As for men, respectively $85 \%$ and $83 \%(p=1.00)$ in the Benchmark sessions and the Identity sessions hold beliefs consistent with winning the individual tournament.

\subsubsection{The effect of social identity on the decision to enter the individual tour- nament}

In Task 3, participants were asked to choose between a piece rate and a tournament, knowing that they would win their tournament if they correctly solved more additions during Task 3 than a randomly chosen opponent (belonging to the other group for the Identity sessions) during Task 2. The most obvious guess would have been that group identity increases the number of participants willing to enter the individual tournament.

In the Benchmark sessions, $51 \%$ of women and $85 \%$ of men chose to enter the tournament (a two-sided Fisher's exact test yields $p=0.00$ ). In the Identity sessions, $32 \%$ of women and $75 \%$ of men $(p=0.00)$ made such a choice. While, in both cases, men chose the tournament significantly more often than women, one can also notice that participants to the Identity sessions entered the competition less often than their counterparts from the Benchmark sessions. Looking closer at these differences in tournament entry between treatments, it appears that while men's decision to enter the tournament is not significantly different between treatments $(p=0.31)$, women from the Identity sessions choose marginally significantly $(p=0.10)$ less often the tournament than women from the Benchmark sessions. Again, the fact that

\footnotetext{
${ }^{5}$ The proportion of men in these sessions varied respectively between $29 \%$ and $69 \%$ for the Benchmark sessions and between $50 \%$ and $69 \%$ in the Identity sessions. However, the correlation between overconfidence (measured as the difference between the participant's task 2 performance, which is known to her, and her guess of the average task 2 performance in her session) and the proportion of men in the session is significant for neither men $(p=0.20)$ nor women $(p=0.72)$.
} 
the proportion of men is higher in the Identity sessions could help explain why fewer women enter the tournament if they think they are less likely to beat a male opponent. However, the correlation between the share of participants choosing to enter the individual tournament and the proportion of men in the session is far from being significant for both men $(p=0.54)$ and women $(p=0.68)$. Furthermore, neither men $(p=0.79)$ nor women $(p=0.37)$ choose to enter the individual tournament more often when the proportion of men is lower than the median proportion of $55 \%$. Women actually enter a bit more often when the proportion of men in their session is above the median proportion of men in all sessions.

Figures 1 and 2 represent, for both treatments, the proportion of men and women of each performance level (below and above the median performance ${ }^{6}$ ) choosing the tournament. It appears that while men from the Benchmark sessions chose the tournament all the more that their performance was high (a two-sided Fisher's exact test yields $p=0.01$ ), the choice of men from the Identity sessions does not seem to depend on their performance level $(p=1.00)$. On the contrary, when high-performing women from the Benchmark sessions do not enter the tournament more often than their low-performing counterparts $(p=1.00)$, women from the Identity sessions seem to be acting more strategically, entering more if their performance is high $(p=0.08)$.

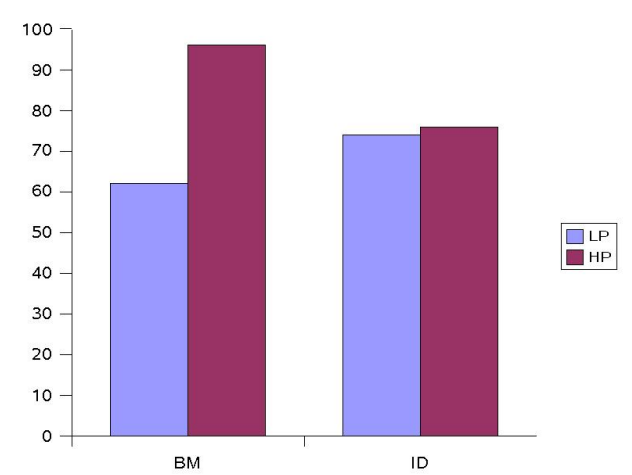

Figure 1. Proportion of low-performing and high-performing men from Benchmark (BM) and Identity (ID) sessions entering the individual tournament.

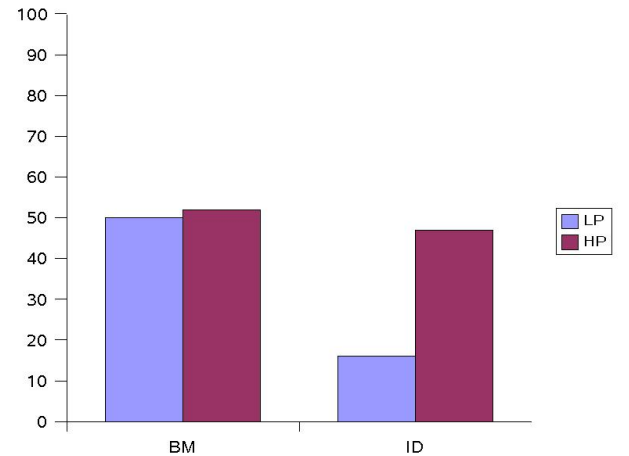

Figure 2. Proportion of low-performing and high-performing women from Benchmark (BM) and Identity (ID) sessions entering the individual tournament.

These first results imply that the attempt to create a group Identity has caused women, and more precisely low-performing women to shy away even more from competition. They

\footnotetext{
${ }^{6}$ The median task 2 performance is respectively 6.85 in the Benchmark sessions and 5.84 in the Identity sessions. Therefore, irrespectively of the treatment they took part in, I consider all participants with a task two performance strictly inferior to 6 as low-performing while all participants with a task 2 performance at least equal to 6 are considered to be high-performing. However, the results do not change qualitatively when considering participants with a performance below or equal to 6 to be low-performing and those with a performance at least equal to 7 to be high-performing.
} 
also tend to show that the membership to a group makes men act less strategically while, if anything, the opposite seems to be true for women.

The regressions reported in table 1 may help us understand these first results by assessing the role of beliefs (Guesswin) and risk, ambiguity and feedback aversion (Submit) in the decision to enter the individual tournament. The dummy variable Submit is equal to 1 if the participant's Task 3 prime decision was to submit her Task 1 performance to the individual tournament, and to 0 otherwise. Task 3 and 3 prime decisions are very similar except for the fact that Task 3 prime does not involve a subsequent performance. In consequence, Task 3 prime allows one to control for everything that can explain the decision to enter the individual tournament (confidence in one's chances of winning, risk, ambiguity and feedback aversion) except for the taste for competition. Since a control for confidence was already included in the regressors (Guesswin), the decision to submit a past performance to the individual tournament adds a new control for risk, ambiguity and feedback aversion.

Table 1: Linear Probability Model of Tournament-Entry Decision (Task 3)

\begin{tabular}{lcccccc}
\hline Regressors & \multicolumn{3}{c}{ Benchmark } & \multicolumn{3}{c}{ Identity } \\
& $(1)$ & $(2)$ & $(3)$ & $(1)$ & $(2)$ & $(3)$ \\
\hline \hline Female & -0.32 & -0.27 & -0.18 & -0.43 & -0.36 & -0.30 \\
& $(0.00)$ & $(0.00)$ & $(0.00)$ & $(0.00)$ & $(0.00)$ & $(0.00)$ \\
Prob & 0.37 & 0.18 & 0.01 & 0.29 & 0.13 & 0.14 \\
& $(0.06)$ & $(0.34)$ & $(0.85)$ & $(0.06)$ & $(0.47)$ & $(0.40)$ \\
Guesswin & & 0.40 & 0.35 & & 0.27 & 0.20 \\
& & $(0.00)$ & $(0.00)$ & & $(0.05)$ & $(0.08)$ \\
Submit & & & 0.16 & & & 0.18 \\
& & & $(0.00)$ & & & $(0.00)$ \\
\hline Observations & 76 & 76 & 76 & 90 & 90 & 90 \\
\hline \hline
\end{tabular}

Linear-probability model using clusters for each participant and each session.

The table presents marginal effects computed at a man with a $50 \%$ chance of winning the tournament. $\mathrm{P}$-values are in brackets.

The first noticeable fact is that, whereas beliefs and risk, ambiguity and feedback aversion help explain part of the gender gap in tournament entry in both the Benchmark and Identity sessions (the coefficient of Female gets closer to zero when adding Guesswin and Submit into the regressors), the residual unexplained gender gap is almost twice as important in the Identity sessions. This suggests that the attempt to create a group Identity has increased women's fear of competition. Section 4 provides some intuitions of why this could be the case. Indeed, women are not significantly less likely to submit a past performance to the individual tournament when they took part in the Identity sessions rather than in the Benchmark 
sessions (a two-sided Fisher's exact test yields $p=0.82$ ) but they are (marginally) significantly less likely to enter the individual tournament $(p=0.10)$.

\subsection{The effect of social identity on entry in the team tournament}

If, as suggested by past experimental evidence (Eckel and Grossman, 2005, Brewer and Kramer, 1986), group identity shifts individual behaviors from self-interest towards the interest of the whole group, one would expect men and especially high-performing men, not to shy away from the team tournament when competing with a fellow group member against two members of the other group. Furthermore, since women from the Benchmark sessions entered the team tournament more often (even if not significantly so) than the individual tournament, one may guess that the goup identity would further increase their willingness to compete as part of a team.

In the Benchmark sessions, $62 \%$ of women and $59 \%$ of men ( $p=0.82$ with a two-sided Fisher's exact test) chose to enter the team tournament. In the Identity sessions, $42 \%$ of women and $69 \%$ of men $(p=0.02)$ made such a choice. In consequence, team competition which was successful in eliminating the gender gap in tournament entry in the Benchmark sessions failed to do so in the Identity sessions. Yet, in both treatments, women choose the tournament more often when it is team based, even if not significantly so $(p=0.48$ in both the Benchmark sessions and the Identity sessions). Again, women are found to enter less often in the team tournament in the Identity sessions than in the Benchmark sessions. Although this difference is only marginally significant (a two-sided Fisher's man test yields $p=0.11$ ), one can wonder whether the higher proportion of men in the Identity sessions is driving this result. As a matter of fact, women are significantly $(p=0.01)$ less likely to enter the team tournament when the proportion of men in their session is above the average proportion in all sessions $(55 \%)$ than when it is below. ${ }^{7}$ Looking separately at the two treatments allows one to see that while women of the Identity sessions are more likely to enter the team tournament when the proportion of men is low (respectively $61 \%$ and $25 \%$ of women in sessions with a low proportion of men and a high proportion of men chose to enter the team tournament, $p<0.05$ ), it is not the case for women from the Benchmark sessions (respectively $70 \%$ and $50 \%$ of women in sessions with a low proportion of men and a high proportion of men chose to enter the team tournament, $p<0.30$ ). These results may suggest that men's behavior during the group identity building activities may have made it difficult for women to feel part of the group.

\footnotetext{
${ }^{7} 66 \%$ of women who took part in sessions with a low proportion of men (less than $55 \%$ of men) entered the team tournament and only $35 \%$ of those who took part in a session with a high proportion of men.
} 
As far as men's behavior is concerned, while, in the Benchmark treatment, men entered the tournament significantly less often when they were part of a team rather than alone $(p=0.02)$, in the Identity treatment, they chose the tournament almost as often whether it was individual or team-based $(p=0.66)$. These patterns can be observed on figures 3 and 4 .

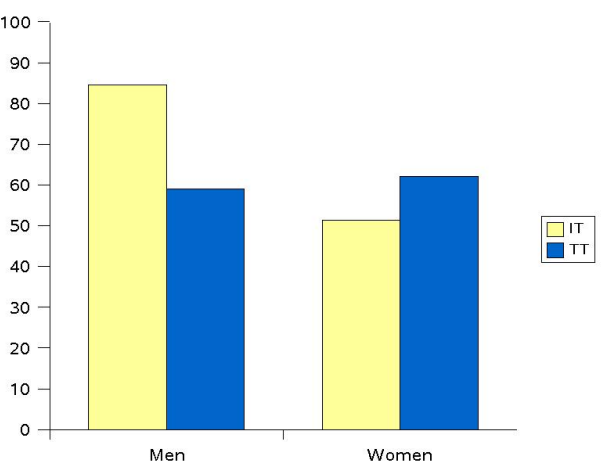

Figure 3. Proportion of men and women from Benchmark sessions entering the individual tournament (IT) and team tournament (TT).

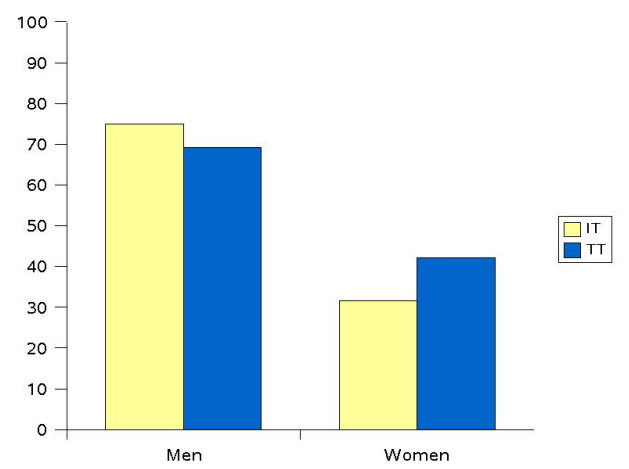

Figure 4. Proportion of men and women from Identity sessions entering the individual tournament (IT) and team tournament (TT).

\subsection{Explanations for the changes in decision to enter the team tour- nament}

In the Benchmark sessions, men choose the individual tournament more often than women but many of them stay out of the tournament when it is team-based while, in the same time, women do not significantly change their competitive behavior, resulting in the elimination of the gender gap in tournament entry when the competition becomes team-based. However, when a group Identity has been built, the team competition no longer induces a change in men's competitive behavior and a gender gap also exists in the team tournament. This subsection aims at further understanding why there is a significant gender gap in team tournament entry in the Identity sessions while there was none in the Benchmark sessions. In particular, this subsection investigates why men no longer react to the competition being team-based when they belong to a social group. Furthermore, as the results concerning the individual tournament suggest that women may be acting more strategically when belonging to a social group (women from the Identity sessions enter the individual tournament all the more that their performance is high when it was not the case in the Benchmark sessions) it also seems interesting to see whether it is also the case in the team tournament.

Figures 5 and 6 are a good illustration of how group identity changes men and women's competitive behavior. In the Benchmark sessions, men entered massively the individual 
tournament but many of them chose not to participate in the team competition unless they knew they would be matched with a teammate of level close to their own. It then seems that men are unwilling to take the chance of being dragged down by a less efficient teammate. However, if group identity makes men act less in their own interest and more in the interest of their group, one could expect men to more easily accept the possibility of losing because of a less able teammate if he or she is a fellow group member. Indeed, when a group identity has been built, men enter at very similar rates in each of the three tournaments. As for women, it seems from figure 6 that the creation of a group identity has just made them less prone to enter each of the three tournaments. Women from the Identity sessions enter marginally significantly less often than their counterparts from the Benchmark sessions the individual tournament (a two-sided exact fisher's test yields $p=0.10$ ) and the standard team tournament $(p=0.10)$ and the difference is more pronounced in the team tournament with ateammate of the same level $(p=0.04)$.

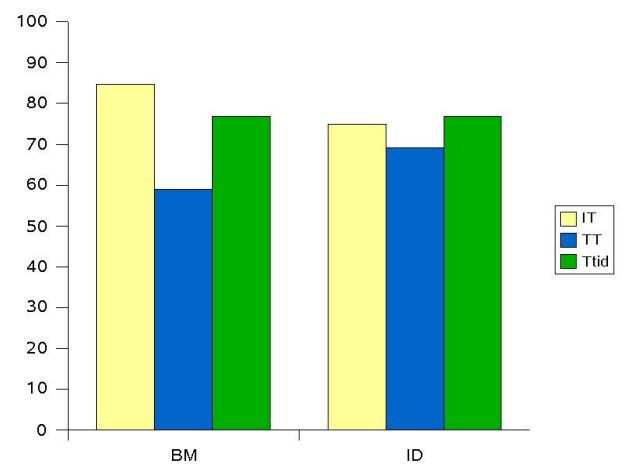

Figure 5. Proportion of men from the Benchmark sessions (BM) and the Identity sessions (ID) entering each of the three tournaments.

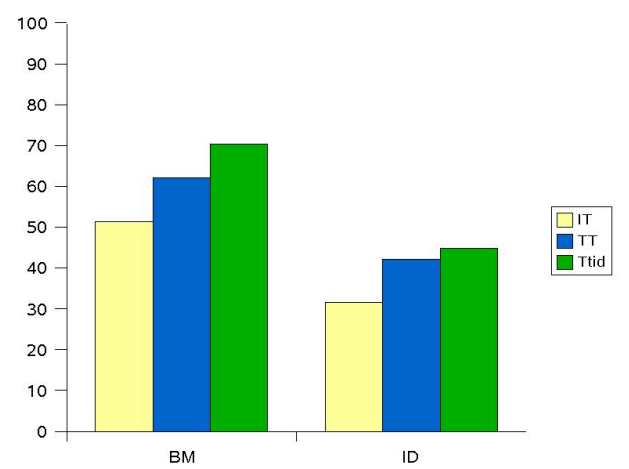

Figure 6. Proportion of women from the Benchmark sessions (BM) and the Identity sessions (ID) entering each of the three tournaments.

The change in decision to enter the team tournament provoked by the creation of a group identity seems to be at least partly driven by a change in the way participants react to the uncertainty on their teammate's ability. It is, however, likely that participants respond differently to this uncertainty depending on their own ability level. Indeed, a participant driven by selfish motives will have more interest in entering the team tournament with a teammate of the same level than the standard team tournament if her own performance is high but the contrary will be true for a low-performing participant (for whom not knowing the level of her teammate is better than knowing than she is also of low performance level).

Figure 7 shows the proportion of entry in each of the three tournaments where participants are broken down by gender and performance level (below and above median). As can be seen on figures (a) and (b), men from the Benchmark sessions have a strategic behavior. Low- 
performing men enter the team tournament more often than the individual tournament so as to take advantage of the performance of a more able teammate. Indeed, they are less likely to choose the team tournament when matched with a teammate of the same (low) level as their own. As for high-performing men, almost all of them enter the individual tournament but a lot of them are repelled from the team tournament by the possibility of being dragged-down by a less able participant (since most of them are willing to enter the team tournament with a teammate of the same level). The creation of a group identity seems to have provoked a change in men's reasons for entering a tournament. In the Identity sessions, men's choice to enter a tournament does not seem to vary with their performance, and it does not seem to depend on the type of tournament (individual vs team-based) either. More precisely, men do not opt out of the tournament when it is team-based. Group membership seems to have make men willing to take the risk of being matched with a less able participant.

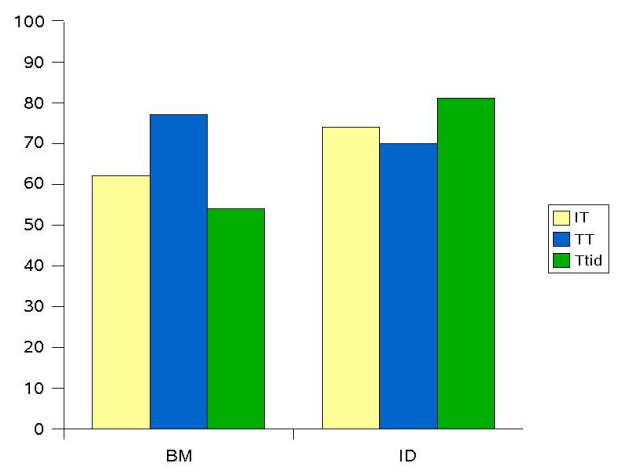

(a) Entry rates of low-performing men

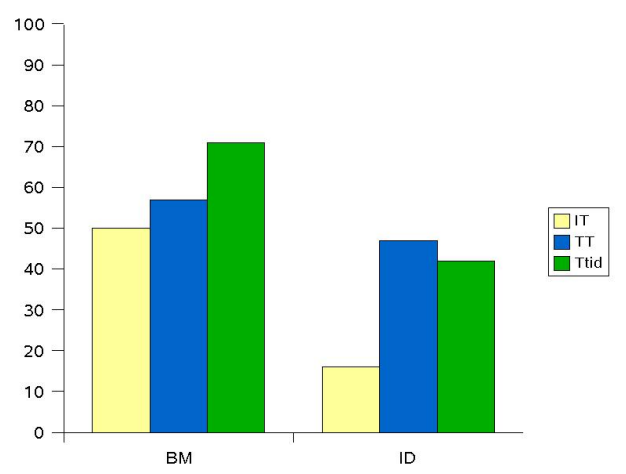

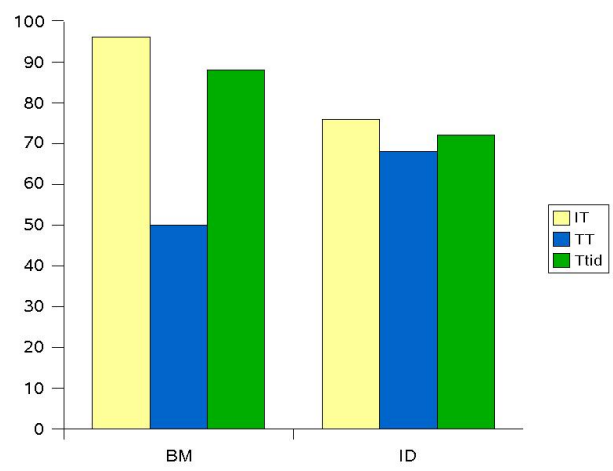

(b) Entry rates of high-performing men

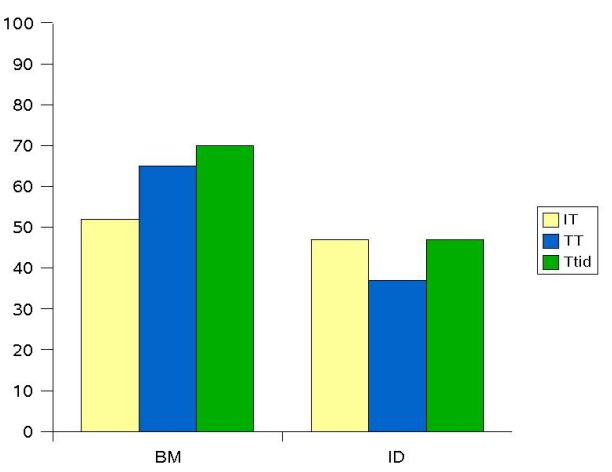

(c) Entry rates of low-performing women (d) Entry rates of high-performing women Figure 7. Entry rates for each of the 3 tournaments by gender and performance level

As for women, in the Benchmark sessions, there seems to be no link between their performance level and their decision to enter a tournament (see figures (c) and (d)). They just 
enter at slightly higher rates when the tournament is team-based rather than individual. On the other hand, in the Identity sessions, women act a bit more strategically, choosing to enter the individual tournament all the more that their performance is high. Furthermore, low-performing women seem to be attracted by the team tournament whether they have information about their teammate's level or not while high-performing women choose the tournament slightly less often when it is team-based except if they know their teammate will be of the same (high) level as their own.

In order to understand what causes participants to enter a given tournament and opt out of the other one, regressions were run using the change in the decision to enter tournaments as the dependent variable. Specifically, the change in tournament entry between the individual tournament and the team tournament and between the team tournament and the team tournament with a teammate of the same level are the dependent variables of the regressions which results are reported in table 2. The regressors include a Female dummy, a PerfLevel dummy which equals 1 if the subject's task 2 performance was above median and 0 otherwise $^{8}$, an Id dummy which equals 1 if the subject took part in one of the Identity sessions and 0 if she took part in a Benchmark session, an interaction term between Female and PerfLevel and an interaction term between Female, PerfLevel and Id.

Table 2: Ordered logit of change in decisions to enter the tournaments

\begin{tabular}{lcccccc}
\hline \multirow{2}{*}{ Regressors } & \multicolumn{3}{c}{ Change between IT and TT } & \multicolumn{3}{c}{ Change between TT and TTid } \\
& BM & ID & All & BM & ID & All \\
\hline \hline Female & 0.27 & -1.46 & -0.69 & -1.39 & 0.62 & -0.14 \\
& $(0.73)$ & $(0.03)$ & $(0.17)$ & $(0.10)$ & $(0.96)$ & $(0.77)$ \\
PerfLevel & -0.24 & 1.77 & 0.75 & 0.37 & -0.60 & -0.19 \\
& $(0.73)$ & $(0.02)$ & $(0.13)$ & $(0.61)$ & $(0.76)$ & $(0.71)$ \\
Female*PerfLevel & -2.27 & 1.59 & -1.18 & 2.65 & -0.87 & 0.38 \\
& $(0.03)$ & $(0.09)$ & $(0.11)$ & $(0.01)$ & $(0.92)$ & $(0.07)$ \\
Id & & & 0.31 & & & -0.28 \\
& & & $(0.45)$ & & & $(0.49)$ \\
Female*PerfLevel*Id & & & 1.64 & & & -1.51 \\
& & & $(0.02)$ & & & $(0.03)$ \\
\hline Observations & 76 & 90 & 166 & 76 & 90 & 166 \\
\hline \hline
\end{tabular}

Ordered logit regressions.

P-values are in brackets.

${ }^{8}$ I tried to include Guesswin rather than PerfLevel into the regressors but it turns out not to be significant. One reason could be that men and women of the same level may not make as confident assessment due to differences in modesty. 
Concerning the change of choice to enter the tournament when it goes from being individual to being team-based, the coefficient of Female*PerfLevel is negative and significant in the Benchmark sessions while it is positive and significant at the $10 \%$ level in the Identity sessions. This shows that, in the Benchmark sessions, high-performing men are more likely than others to enter the individual tournament but opt out of the team tournament, while, in the Identity sessions, high-performing men are less likely to exhibit this behavior in comparison to others. In the regression of the whole pool of participants, the coefficient of Female*PerfLevel ${ }^{*}$ Id is positive and significant which confirms that group identity makes high-performing men less likely to shy away from team competition.

Looking at how competitive behaviors change between the standard team tournament (TT) and the team tournament with a teammate of the same level (TTid), it appears that high-performing men from the Benchmark sessions are more likely than others to favor the TTid over the TT, since Female*PerfLevel is positive and highly significant, while it is not the case in the Identity sessions. The negative and significant coefficient of Female*PerfLevel*Id in the regressions concerning all participants confirms that when their teammate is a fellow group member, high-performing men are less likely in comparison with other participants to refuse to enter the team tournament unless they are matched with a teammate of similar performance level.

In order to understand if these results come from men becoming less selfish or from women becoming more selfish when belonging to a social group, separate regressions were run for men and women which results are reported in table 3.

Table 3: Ordered logit of change in decisions to enter the tournaments by gender

\begin{tabular}{lcccc}
\hline Regressors & \multicolumn{2}{c}{ Change between IT and TT } & \multicolumn{2}{c}{ Change between TT and TTid } \\
& Men & Women & Men & Women \\
\hline \hline Id & 0.92 & -0.78 & -1.37 & 0.67 \\
& $(0.24)$ & $(0.27)$ & $(0.07)$ & $(0.36)$ \\
PerfLevel & 2.64 & -0.22 & -2.41 & 0.32 \\
& $(0.00)$ & $(0.74)$ & $(0.00)$ & $(0.64)$ \\
Id*PerfLevel & -2.44 & 1.58 & 2.72 & -0.88 \\
& $(0.02)$ & $(0.10)$ & $(0.01)$ & $(0.37)$ \\
\hline Observations & 91 & 75 & 91 & 75 \\
\hline \hline
\end{tabular}

Ordered logit regressions.

$\mathrm{P}$-values are in brackets.

It appears that the results are mainly driven by high-performing men being both, less likely to enter the individual tournament and opt out from the standard team tournament, 
and less likely to only enter the competition when they know their teammate will be of level close to their own (The coefficient of $\mathrm{Id}^{*}$ PerfLevel is positive and highly significant in the regression of the change in entry between the TT and the TTid). As far as the women are concerned, one can only say that group identity makes high-performing women marginally significantly $(p=0.10)$ more likely to enter the individual tournament than the team tournament. However, women from the Identity sessions do not favor all the more the team tournament with a teammate of the same level over the standard team tournament that their performance is high (the coefficient of $\mathrm{Id}^{*}$ PerfLevel does not reach significance in the regression of the change between the TT and the TTid concerning women).

\section{Discussion}

The creation of a group identity has led to clear changes in men's behavior who have become less selfish and more likely to take actions which benefit the members of their group. Women are even less competitive once they went through the group-identity-building activities and, if anything, act more selfishly.

High-performing men become more prone to help a possibly less efficient teammate get higher payoffs if he or she is a fellow group member, while low-performing men are less likely to take advantage of a probably more efficient teammate when they belong to the same social group. This is in line with the idea that group identity shifts behaviors from individual interest towards the interest of the whole group. Indeed, Eckel and Grossman (2005) found that a strong induced identity succeeds in reducing individual shirking behaviors and free-riding in public goods games. Wit and Wilke (1992)'s results also suggest that group categorization elicits more cooperation than individual categorization. The perception of sharing a common fate has furthermore been found to lead to more self-restraint in a commonressource dilemma (Brewer and Kramer, 1986). Tajfel and Turner (1986) also showed that individuals who perceive themselves as members of a social group want to maximize the inter-group outcome difference which may explain why men become more willing to enter a team competition against an outgroup team.

Women's reaction to the creation of a social identity is more surprising. The first noticeable fact is that the group identity seems to have decreased low-performing women's willingness to enter competitive environments. Another change in women's behavior caused by the creation of a group identity is that low-performing women tend to be less hesitant to take advantage of a more efficient teammate when they belong to her group. This last result is nevertheless only a tendency as it does not reach statistical significance. In any 
case, women do not experience the same shift in their behavior towards acting more in the interest of their group as men do. One can only venture some reasons why this may be the case.

Firstly, and perhaps most likely, the attempt at creating a group identity may not have been as successful for women as it has been for men and it may even have made women uncomfortable. As a result, women may not perceive themselves as belonging to their group or they may not feel as included as men do. Some past experimental findings back up this interpretation of women's behavior. Cadsby and Maynes (1998) found that their attempt to create a group identity decreased women's contributions in early rounds of the public good game. They blame it on the fact that the activity meant to build a group identity failed to do so for women as they did not seem to have enjoyed it. In the same vein, Brown-Kruse and Hummels (1993) found an effect of the creation of a group identity for men who contribute more to the public good when belonging to a group, but none for women.

Secondly, women may perceive themselves as members of their group but not react to this group identity in the same way men do. For instance, while low-performing men feel less entitled to take advantage of a probably more able participant if he is a fellow group member rather than a total stranger, women may, on the contrary, be more comfortable dragging down a member of their social group than a random participant.

Finally, as group identity may increase the feeling of accountability towards fellow group members, it could be the case that women react by shying away even more from competition so as not to interfere with their group members' outcomes and utility in general (as they may even perceive a setback in the individual tournament as hurting their group). This would nevertheless not explain why women tend to take advantage of a more efficient teammate more often when he or she is a member of their group rather than a random participant.

Regarding the consequences in terms of efficiency, group identity allows to get highperforming men to self-select into the team competition even when they do not know that their teammate is also of high ability. This could lead to positive externalities as, in time, one could improve her own performance when matched with a more able teammate. One can for instance think that working with an experienced employee could help an untrained worker gain competence. An underachieving student could as well benefit from studying with a successful peer.

In opposition to men's behavior, women's tendency to shy away even more from competition when belonging to a group and, potentially, acting less as team players than when surrounded by random people, has a negative impact on both parity and efficiency. The important point is to find out whether women's reaction to group identity is an artefact of 
the lab or whether women would act in the same way in real life. I would tend to think that women did not enjoy the group-identity-building activities participants had to go through as much as men did. Looking at the discussions through the instant message system provide some indications that it may be the case. A first result is that men intervened more often than women through this system (comparing the number of interventions by male and femele participants, a two-sided Mann-Whitney test yields $p=0.06$ ). It is also the case that men were more likely to come up with a name for the group they belonged to. Over the $12^{9}$ participants who proposed the group name which was eventually chosen by the group members, 8 were men. Finally, women from the Identity sessions are less likely to self-select into the team competition when the proportion of men in their session is high. This is not the case for women from the Benchmark sessions.

\section{Conclusion}

Recent experimental research papers are interested in how social identity affects individual behavior. Most existing results focus on self-other allocation games (Chen and Li, 2009), social dilemmas or public-goods games (Charness et al., 2007, Sutter, 2009, Eckel and Grossman, 2005). This article studies the effect of an artificially created group identity on participants' willingness to compete either alone or as part of a team. Prior to taking decisions about whether to enter various competitive environments, participants were randomly separated into two groups and could use an instant message system to communicate with their fellow group members. Using this communication system, they had to find a name for their group and then answer a four-question quiz which was meant to build a sense of group membership.

The main result is that, while team competition was successful in eliminating the gender gap in tournament entry in the Benchmark sessions, it is no longer the case in the Identity sessions. The reason lies in men's behavior and, more precisely, in high-performing men's behavior who opt out of team competition in the Benchmark sessions because they dread being matched with a less able teammate but overcome this fear when their teammate is a fellow group member.

This result suggests that high-performing men are more comfortable working in teams with teammates they perceive as belonging to the same circles as they do. Indeed, Montgomery (1991) finds that 50 percent of workers employed at the time of their study got their

\footnotetext{
${ }^{9}$ There were five sessions and participants of each session were divided into two groups but in one of the 10 groups three participants each came up with a part of the group name.
} 
job through friends or relatives. This could also help explain why alumni from a given university often try to hire graduates from the same university. According to Rebick (2000), more than half of all hires on the japanese job market can be attributed to employers' persistence to hire graduates from the same universities.

Another finding of this article is that low-performing women become less willing to compete and, if anything, less socially-oriented when one tried to instill them a sense of group membership. As for high-performing women, they do not display any sign of "group spirit" either. It is nevertheless difficult to reach a definite conclusion as to whether this is because the group identity building activities failed to make women feel included in their group or because women are not as prone as men to cliquish behaviors.

Future research may study how the nature of social groups affects one's willingness to compete as part of a team as Solow and Kirkwood (2002) show that contributions to public goods are sensible to this issue. It could also be interesting to find out how knowing the gender of one's other group members influences competitive behaviors. 


\section{References}

Akerlof, G. A. and R. E. Kranton (2000). Economics and identity. Quarterly Journal of Economics 115(3), 715-753.

Akerlof, G. A. and R. E. Kranton (2002). Identity and schooling: Some lessons for the economics of education. Journal of Economic Literature 40(4), 1167-1201.

Akerlof, G. A. and R. E. Kranton (2005). Identity and the economics of organizations. Journal of Economic Perspective 19(1), 9-32.

Altonji, J. and R. Blank (1999). Handbook of Labor Economics, Volume 3, Chapter Race and Gender in The Labor Market, pp. 3144-3259. Elsevier Science.

Brewer, Marilynn, B. and M. Kramer, Roderick (1986). Choice behavior in social dilemmas: Effects of social identity, group size, and decision framing. Journal of Personality and Social Psychology 50, 543-549.

Brown-Kruse, J. and D. L. Hummels (1993). Gender effects in public goods contribution: do individuals put their money where their mouth is? Journal of Economic Behavior and Organization 22, 255-267.

Cadsby, C. B. and E. Maynes (1998). Gender and free riding in a threshold public goods game: experimental evidence. Journal of Economic Behavior and Organization 34(4), 603-620.

Charness, G., L. Rigotti, and A. Rustichini (2007). Individual behavior and group membership. American Economic Review 97, 1340-1352.

Chen, Y. and S. X. Li (2009, March). Group identity and social preferences. American Economic Review 99(1), 431-457.

Dargnies, M.-P. (2009). Team competition: eliminating the gender gap in competitiveness.

Eckel, C. and P. Grossman (2005). Managing diversity by creating team identity. Journal of Economic Behavior and Organization 58(3), 371-392.

Goldin, C. and C. Rouse (2000). Orchestrating impartiality: The impact of "blind" auditions on female musicians. American Economic Review 90, 715-741.

Greiner, B. (2004). An Online Recruitment System for Economic Experiments. (Kremer, K.,Macho, V., (Eds.), ed.). 
Gupta, N., A. Poulsen, and M.-C. Villeval (2005). Male and female competitive behavior: Experimental evidence. IZA Discussion Paper No. 1833.

Montgomery, James, D. (1991). Social networks and labor-market outcomes: Toward an economic analysis. American Economic Review 81(5), 1408-1418.

Niederle, M., C. Segal, and L. Vesterlund (2008). How costly is diversity? affirmative action in competitive environments. NBER Working Paper NO. W13923.

Niederle, M. and L. Vesterlund (2007). Do women shy away from competition? do men compete too much? Quarterly Journal of Economics 122, 1067-1101.

Rebick, Marcus, E. (2000). The importance of networks in the market for university graduates in japan: a longitudinal analysis of hiring patterns. Oxford Economics Papers 52, Rebick.

Solow, J. L. and N. Kirkwood (2002). Group identity and gender in public goods experiments. Journal of Economic Behavior and Organization 48(4), 403-412.

Sutter, M. (2009). Individual behavior and group membership: Comment. Forthcoming in American Economic Review.

Tajfel, H. (1970). Experiments in intergroup discrimination. Scientific American 223, 96102.

Tajfel, H., M. Billig, R. Bundy, and C. L. Flament (1971). Social categorization and intergroup behavior. European Journal of Social Psychology 1, 149-177.

Tajfel, H. and J. Turner (1979). An integrative theory of intergroup conflict. In S. Worchel and W. Austin (Eds.), The Social Psychology of Intergroup Relations, Monterey, CA: Brooks/Cole.

Tajfel, H. and J. Turner (1986). The social identity theory of intergroup behavior. In S. Worchel and W. Austin (Eds.), The Social Psychology of Intergroup Relations, Chicago,: Nelson-Hall.

Wit, A. P. and H. A. M. Wilke (1992). The effect of social categorization on cooperation in three types of social dilemmas. Journal of Economic Psychology 13, 135-151.

Zeiliger, R. (2000). A presentation of regate, internet based software for experimental economics. http://www.gate.cnrs.fr/ zeiliger/regate/RegateIntro.ppt, GATE. 


\section{Instructions}

\section{Benchmark sessions}

The experiment is composed of 8 tasks. Before each task, you will be carefully explained what the task is about and have the opportunity to ask as many questions as you need. Please remember that you are not allowed to communicate in any way with one another. At the end of the experiment two of the eight tasks you will have completed will be randomly chosen to determine your payoffs.

Task 1. Piece Rate: In task 1, you will have 3 minutes to solve as many additions of 5 two-digits numbers as you can. You are allowed to use the scratch paper you have been given. If Task 1 is one of the two tasks randomly chosen for payment, you will receive 50 cents per addition correctly solved. At the end of Task 1, a screen will indicate you how many additions you solved correctly.

\section{NEXT PAGE}

Task 2. Individual Tournament: You will have 3 minutes to solve as many additions of 5 two-digits numbers as you can. If Task 2 is chosen for payment, you will receive 1 euro per correct answer if you solved more additions than a randomly chosen opponent present in the room, otherwise you will receive nothing. You will earn 50 cents per addition correctly solved in case of a tie.

At the end of Task 2, a screen will indicate how many additions you solved correctly but you will know whether you won your tournament only at the end of the experiment.

\section{NEXT PAGE}

Task 3. Choice between Piece Rate and Individual Tournament: Before performing your 3 minutes of additions, you will have to choose whether you want to be paid according to the Piece Rate (50 cents per correct answer) or the Individual Tournament compensation scheme.

If you choose the Piece Rate, you will receive 50 cents per addition correctly solved during Task 3.

If you select the tournament, you will receive 1 euro per correct answer if your Task 3 performance exceeds the Task 2 performance of a randomly chosen opponent, otherwise you will receive nothing. You will earn 50 cents per addition correctly solved during Task 3 in case of a tie.

At the end of Task 3, a screen will indicate how many additions you solved correctly but you 
will know whether you won your tournament, if you choose to engage in it, only at the end of the experiment.

NEXT PAGE

Task $4^{10}$. Choice between submitting Task 1 performance to Piece Rate or Individual Tournament: No additions to do here, the performance which will determine your payoffs is your Task 1 performance.

If you choose to submit your Task 1 performance to the Piece Rate, you will receive 50 cents times your Task 1 performance.

If you choose to submit your Task 1 performance to the individual tournament, you will receive 1 euro per addition correctly solved in Task 1 if you solved more additions in Task 1 than your randomly chosen opponent, otherwise you will receive nothing. You will earn 50 cents per addition correctly solved during Task 1 in case of a tie.

You will know whether you won your tournament, if you choose to submit your Task 1 performance to the tournament, only at the end of the experiment.

\section{NEXT PAGE}

Task $5^{11}$. Choice between Piece Rate and Team Tournament: You have to choose whether they want to be paid according to the Piece Rate or the Team Tournament. The Team Tournament is a two to two competition.

If you choose the Piece Rate, you will receive 50 cents per addition correctly solved during Task 4.

If you choose the Team Tournament, two opponents will be randomly drawn among the other participants present in the room. One teammate will be randomly drawn among the participants who chose the team tournament. If the number of additions solved by your team during Task 4 exceeds the number of additions solved by the opposing team during Task 2, each teammate of your team will receive 1 euro times the average score of the team. Otherwise, you will receive nothing. You and your teammate will each earn 50 cents times the average score of the team during Task 4 in case of a tie.

At the end of Task 4, a screen will indicate how many additions you solved correctly but you will know whether you won your tournament, if you choose to engage in it, only at the end of the experiment. You will not know either your teammate's performance until the end of the experiment.

\section{NEXT PAGE}

\footnotetext{
${ }^{10}$ Task 4 is referred to as Task 3 prime in the core of the paper

${ }^{11}$ Task 5 is referred to as Task 4 in the core of the paper
} 


\section{Task $6^{12}$. Choice between submitting Task 1 performance to Piece Rate or Team}

Tournament: No additions to do here, the performance which will determine your payoff is your Task 1 performance.

If you choose to submit your Task 1 performance to the Piece Rate, you will receive 50 cents times your Task 1 performance.

If you choose to submit your Task 1 performance to the Team Tournament, two opponents are randomly drawn among the other participants present in the room. One teammate is randomly drawn among the participants who chose to submit to the Team Tournament. If the number of additions solved by your team during Task 1 exceeds the number of additions solved by the opposing team during Task 1, you and your teammate will each receive 1 euro times the average score of the team. Otherwise, you will receive nothing. You and your teammate will each earn 50 cents times the average score of the team during Task 1 in case of a tie.

\section{NEXT PAGE}

\section{Task $7^{13}$. Choice between Piece Rate and Team Tournament with a teammate of the same level (TTid henceforth):}

If you choose the Piece Rate, you will receive 50 cents per addition correctly solved during task 5 .

If you choose the Team Tournament with a teammate of the same level, two opponents will be randomly drawn among the other participants present in the room. Your teammate will be the participant, who chose the team tournament with a teammate of the same level, whose Task 2 performance was the closest to your own Task 2 performance. If the number of additions solved by your team during Task 5 exceeds the number of additions solved by the opposing team during Task 2, you and your teammate will each receive 1 euro times the average Task 5 score of your team. Otherwise, you and your teammate will receive nothing. You and your teammate will each earn 50 cents times the average score of the team during Task 5 in case of a tie.

At the end of Task 5, a screen will indicate how many additions you solved correctly but you will know whether you won your tournament, if you choose to engage in it, only at the end of the experiment. You will not know either your teammate's performance until the end of the experiment.

\section{NEXT PAGE}

\footnotetext{
${ }^{12}$ Task 6 is referred to as Task 4 prime in the core of the paper

${ }^{13}$ Task 7 is referred to as Task 5 in the core of the paper
} 


\section{Task $8^{14}$. Choice between submitting Task 1 performance to Piece Rate or Team} Tournament with a teammate of the same level: No additions to do here, the performance which will determine your payoff is your Task 1 performance.

If you choose to submit your task 1 performance to the Piece Rate, you will receive 50 cents times your Task 1 performance.

If you choose to submit your task 1 performance to the team tournament with a teammate of the same level, two opponents will be randomly drawn from among the other participants present in the room. Your teammate will be the participant, who chose to submit to the team tournament with a teammate of the same level, whose Task 2 performance was the closest to your own Task 2 performance. If the number of additions solved by your team during Task 1 exceeds the number of additions solved by the opposing team during Task 1 , you and your teammate will each receive 1 euro times the average score of their team. Otherwise, you and your teammate will receive nothing. You and your teammate will each earn 50 cents times the average score of the team during Task 1 in case of a tie.

\section{NEXT PAGE}

Belief-assessment Questions The experiment is now almost over. You just have to answer a few questions about the experiment. For each correct guess, you will earn 1 additional euro.

At Task 4, whether you chose to enter the team tournament or not, two opponents were randomly drawn among the other participants present in the room. One teammate was randomly drawn among the participants who chose the Team Tournament. Knowing that your own Task 2 performance will be recalled to you on the next screen, please guess the task 2 performances of your 2 opponents and your teammate. Also guess the Task 2 performance of the average participant present in the room.

\section{Identity sessions}

You have been randomly split into two groups of equal size by the computer. Nevertheless, you cannot know who in this room belongs and does not belong to your group and it is important that it remains this way. There will be three phases to this experiment. I will explain clearly what each phase is about before it begins and you will have the opportunity to ask as many clarifying questions as you need.

\footnotetext{
${ }^{14}$ Task 8 is referred to as Task 5 prime in the core of the paper
} 


\section{First phase}

In this first phase, all you have to do is find a name for your group. In order to do so, you will be able to use an instant message system to communicate whithin your group. Of course, you will be unable to communicate with members of the other group. You will have 2 minutes to discuss what name you want to give to your group. Remember that it is important that you do not find out who is and is not in your group, so please try not to provide information on yourself that could give you away. At the end of the three minutes, the message system's window will close and a new screen will appear with a space for you to enter the name you chose. If all members in your group failed to agree on a name, I will pick the name chosen by a majority of members. I will then publicly announce the name chosen by both groups.

\section{Second phase}

In the second phase, you have to answer a four-question quiz with your group. For each question, you have two minutes to discuss through the instant message system what you think is the good answer among the four possibilities. At the end of the two minutes, you have to click on the possibility which you think is the right answer. The answer validated for your whole group is the one chosen by a majority of members. You will earn 1 euro per correct answer validated for your group. Please note that if say, the correct answer is answer A and you selected answer A but all your fellow group members chose answer B, you will earn nothing for this question since the answer validated for you and your all group is (incorrect) answer B. You will know the correct answers and how much you made during this second phase only at the end of the experiment.

\section{Third phase}

The third phase is composed of 8 tasks. Before each task, you will be carefully explained what the task is about and have the opportunity to ask as many questions as you need. Please remember that you are not allowed to communicate in any way with one another. At the end of the experiment two of the eight tasks you will have completed will be randomly chosen to determine your payoffs.

Task 1. Piece Rate: In task 1, you will have 3 minutes to solve as many additions of 5 two-digits numbers as you can. You are allowed to use the scratch paper you have been given. If Task 1 is one of the two tasks randomly chosen for payment, you will receive 50 cents per addition correctly solved. At the end of Task 1, a screen will indicate you how many additions you solved correctly. 


\section{NEXT PAGE}

Task 2. Individual Tournament: You will have 3 minutes to solve as many additions of 5 two-digits numbers as you can. If Task 2 is chosen for payment, you will receive 1 euro per correct answer if you solved more additions than your opponent randomly chosen among the members of the other group, otherwise you will receive nothing. You will earn 50 cents per addition correctly solved in case of a tie.

At the end of Task 2, a screen will indicate how many additions you solved correctly but you will know whether you won your tournament only at the end of the experiment. At the end of the experiment, you will find out how many members of your group won their tournament.

\section{NEXT PAGE}

Task 3. Choice between Piece Rate and Individual Tournament: Before performing your 3 minutes of additions, you will have to choose whether you want to be paid according to the Piece Rate (50 cents per correct answer) or the Individual Tournament compensation scheme.

If you choose the Piece Rate, you will receive 50 cents per addition correctly solved during Task 3.

If you select the tournament, you will receive 1 euro per correct answer if your Task 3 performance exceeds the Task 2 performance of an opponent randomly chosen among the members of the other group, otherwise you will receive nothing. You will earn 50 cents per addition correctly solved during Task 3 in case of a tie.

At the end of Task 3, a screen will indicate how many additions you solved correctly but you will know whether you won your tournament, if you choose to engage in it, only at the end of the experiment. At the end of the experiment, you will find out how many members of your group and of the other group chose the tournament and how many won it.

\section{NEXT PAGE}

\section{Task $4^{15}$. Choice between submitting Task 1 performance to Piece Rate or Indi-} vidual Tournament: No additions to do here, the performance which will determine your payoffs is your Task 1 performance.

If you choose to submit your Task 1 performance to the Piece Rate, you will receive 50 cents times your Task 1 performance.

If you choose to submit your Task 1 performance to the individual tournament, you will receive 1 euro per addition correctly solved in Task 1 if you solved more additions in Task

\footnotetext{
${ }^{15}$ Task 4 is referred to as Task 3 prime in the core of the paper
} 
1 than your opponent randomly chosen among the members of the other group, otherwise you will receive nothing. You will earn 50 cents per addition correctly solved during Task 1 in case of a tie.

You will know whether you won your tournament, if you choose to submit your Task 1 performance to the tournament, only at the end of the experiment. At the end of the experiment, you will find out how many members of your group and of the other group chose the tournament and how many won it.

\section{NEXT PAGE}

Task $5^{16}$. Choice between Piece Rate and Team Tournament: You have to choose whether they want to be paid according to the Piece Rate or the Team Tournament. The Team Tournament is a two to two competition.

If you choose the Piece Rate, you will receive 50 cents per addition correctly solved during Task 4.

If you choose the Team Tournament, two opponents will be randomly drawn among the members of the other group. One teammate will be randomly drawn among the members of your group who chose the team tournament. If the number of additions solved by your team during Task 4 exceeds the number of additions solved by the opposing team during Task 2, each teammate of your team will receive 1 euro times the average score of the team. Otherwise, you will receive nothing. You and your teammate will each earn 50 cents times the average score of the team during Task 4 in case of a tie.

At the end of Task 4, a screen will indicate how many additions you solved correctly but you will know whether you won your tournament, if you choose to engage in it, only at the end of the experiment. You will not know either your teammate's performance until the end of the experiment.

If you choose the tournament, you will only know whether you won it at the end of the experiment. At the end of the experiment, you will find out how many members of your group and of the other group chose the tournament and how many won it.

\section{NEXT PAGE}

\section{Task $6^{17}$. Choice between submitting Task 1 performance to Piece Rate or Team}

Tournament: No additions to do here, the performance which will determine your payoff is your Task 1 performance.

If you choose to submit your Task 1 performance to the Piece Rate, you will receive 50 cents

\footnotetext{
${ }^{16}$ Task 5 is referred to as Task 4 in the core of the paper

${ }^{17}$ Task 6 is referred to as Task 4 prime in the core of the paper
} 
times your Task 1 performance.

If you choose to submit your Task 1 performance to the Team Tournament, two opponents are randomly drawn among the members of the other group. One teammate is randomly drawn among the members of your group who chose to submit to the Team Tournament. If the number of additions solved by your team during Task 1 exceeds the number of additions solved by the opposing team during Task 1, you and your teammate will each receive 1 euro times the average score of the team. Otherwise, you will receive nothing. You and your teammate will each earn 50 cents times the average score of the team during Task 1 in case of a tie.

If you choose the tournament, you will only know whether you won it at the end of the experiment. At the end of the experiment, you will find out how many members of your group and of the other group chose the tournament and how many won it.

\section{NEXT PAGE}

\section{Task $7^{18}$. Choice between Piece Rate and Team Tournament with a teammate of the same level (TTid henceforth):}

If you choose the Piece Rate, you will receive 50 cents per addition correctly solved during task 5 .

If you choose the Team Tournament with a teammate of the same level, two opponents will be randomly drawn among the members of the other group. Your teammate will be the member of your group, who chose the team tournament with a teammate of the same level, whose Task 2 performance was the closest to your own Task 2 performance. If the number of additions solved by your team during Task 5 exceeds the number of additions solved by the opposing team during Task 2 , you and your teammate will each receive 1 euro times the average Task 5 score of your team. Otherwise, you and your teammate will receive nothing. You and your teammate will each earn 50 cents times the average score of the team during Task 5 in case of a tie.

At the end of Task 5, a screen will indicate how many additions you solved correctly but you will know whether you won your tournament, if you choose to engage in it, only at the end of the experiment. You will not know either your teammate's performance until the end of the experiment.

If you choose the tournament, you will only know whether you won it at the end of the experiment. At the end of the experiment, you will find out how many members of your group and of the other group chose the tournament and how many won it.

\section{NEXT PAGE}

\footnotetext{
${ }^{18}$ Task 7 is referred to as Task 5 in the core of the paper
} 


\section{Task $8^{19}$. Choice between submitting Task 1 performance to Piece Rate or Team} Tournament with a teammate of the same level: No additions to do here, the performance which will determine your payoff is your Task 1 performance.

If you choose to submit your task 1 performance to the Piece Rate, you will receive 50 cents times your Task 1 performance.

If you choose to submit your task 1 performance to the team tournament with a teammate of the same level, two opponents will be randomly drawn from among the members of the other group. Your teammate will be the member of your group, who chose to submit to the team tournament with a teammate of the same level, whose Task 2 performance was the closest to your own Task 2 performance. If the number of additions solved by your team during Task 1 exceeds the number of additions solved by the opposing team during Task 1 , you and your teammate will each receive 1 euro times the average score of their team. Otherwise, you and your teammate will receive nothing. You and your teammate will each earn 50 cents times the average score of the team during Task 1 in case of a tie.

If you choose the tournament, you will only know whether you won it at the end of the experiment. At the end of the experiment, you will find out how many members of your group and of the other group chose the tournament and how many won it.

\section{NEXT PAGE}

Belief-assessment Questions The experiment is now almost over. You just have to answer a few questions about the experiment. For each correct guess, you will earn 1 additional euro.

At Task 4, whether you chose to enter the team tournament or not, two members of the other group were randomly drawn among the other participants present in the room. One teammate was randomly drawn among the members of your own group who chose the Team Tournament. Knowing that your own Task 2 performance will be recalled to you on the next screen, please guess the task 2 performances of your 2 opponents and your teammate. Also guess the Task 2 performance of the average participant of your group and of the average participant of the other group.

\section{Quiz questions}

- Question 1: Who was the French president at the beginning of the 60's?

René Coty Charles de Gaulles ${ }^{20}$ Vincent Auriol Georges Pompidou

\footnotetext{
${ }^{19}$ Task 8 is referred to as Task 5 prime in the core of the paper

${ }^{20}$ correct answer
} 
- Question 2: Which is the most populated country in Africa?

Egypt Ethiopia Nigeria ${ }^{20}$ Democratic republic of the Congo

- Question 3: Who said: "The pessimist sees difficulty in every opportunity. The optimist sees the opportunity in every difficulty."

Winston Churchill ${ }^{20}$ Abraham Lincoln Nelson Mandela Ernesto "Che" Guevara

- Question 4: What is the capital of australia?

Sidney Canberra ${ }^{20}$ Melbourne Perth 
DISCUSSION PAPERS 2011

Marie-Pierre Men too sometimes shy away from competition:

SP II $2011-201$

Dargnies

The case of team competition

Marie-Pierre Social Identity and Competitiveness

SP II $2011-202$ 
Bei Ihren Bestellungen von WZB-Papers schicken Sie bitte unbedingt einen an Sie adressierten Aufkleber mit sowie je paper eine Briefmarke im Wert von 0,51 Euro oder einen "Coupon Reponse International " (für Besteller aus dem Ausland)
Please send a self addressed label and postage stamps in the amount of 0.51 Euro or a "CouponReponse International" (if you are ordering from outside Germany) for each WZB-paper requested

\section{Absender / Return Address:}

Wissenschaftszentrum Berlin

für Sozialforschung

Presse- und Informationsreferat

Reichpietschufer 50

D-10785 Berlin-Tiergarten

Hiermit bestelle ich folgende(s) Discussion paper(s):

Bestell-Nr. / Order no.
Please send me the following Discussion paper(s):

Autor/in, Kurztitel /Author(s) / Title(s) in brief 